\title{
Author's Response to Peer Reviews of "The Influence of COVID-19 Vaccination on Daily Cases, Hospitalization, and Death Rate in Tennessee, United States: Case Study"
}

Ali Roghani, PhD

Division of Epidemiology, University of Utah, Salt Lake City, UT, United States

Corresponding Author:

Ali Roghani, PhD

Division of Epidemiology

University of Utah

383 Colorow Drive

Salt Lake City, UT, 84108

United States

Phone: 12104105779

Email: aliroghani@hotmail.com

\section{Related Articles:}

Preprint (medRxiv): https://www.medrxiv.org/content/10.1101/2021.03.16.21253767v1

Preprint (JMIR Preprint): https://preprints.jmir.org/preprint/29324

Peer-Review Report by Anonymous: https://med.jmirx.org/2021/3/e32461/

Peer-Review Report by Anonymous: https://med.jmirx.org/2021/3/e32462/

Published Article: https://med.jmirx.org/2021/3/e29324/

(JMIRx Med 2021;2(3):e32459) doi: 10.2196/32459

\section{KEYWORDS}

COVID-19; pandemic; vaccination; vaccine; strategy; vaccination strategy; hospitalization; mortality rates; older adults; mortality

This is the author's response to peer-review reports for "The Influence of COVID-19 Vaccination on Daily Cases, Hospitalization, and Death Rate in Tennessee, United States: Case Study.”

\section{Round 1 Review}

The author of the manuscript [1] is grateful to the editor and reviewers [2,3] for their invaluable input and feedback.

\section{Anonymous Reviewer [2]}

\section{Specific Comments}

\section{Major Comments}

1. Thank you for your comment. I have updated the title based on the suggestion.

2. Thank you for your suggestion. I have added arguments and statistics to the Introduction.

3. I have developed a section for measures.

4. Thank you for your recommendation. I have developed a Methods section based on your suggestion.

5. Thank you for your comment; it is an important point. My preliminary analysis showed that the results were fairly consistent up to the first month of vaccination. Additionally, it takes time to see the effectiveness of vaccination. Therefore, this study began on the first day of vaccination.

\section{Minor Comments}

1. Thank you. I have reviewed the writing and have improved it.

2. I have changed it.

3. I have changed it.

4. Thank you. I have changed the language.

\section{Anonymous Reviewer [3]}

\section{Specific Comments}

\section{Major Comments}

1. I have added in a study that discusses another methodology, which was different from the US vaccine policy.

2. Thank you. I have developed a section for measures and statistical analysis.

3. Thank you. I have added a section on implications.

\section{Minor Comments}

1. I have reviewed the paper's write-up.

\section{References}


1. Roghani A. The Influence of COVID-19 Vaccination on Daily Cases, Hospitalization, and Death Rate in Tennessee, United States: Case Study. JMIRx Med 2021 Aug;2(3):e29324 [FREE Full text] [doi: 10.2196/29324]

2. Anonymous. Peer Review of "The Influence of COVID-19 Vaccination on Daily Cases, Hospitalization, and Death Rate in Tennessee, United States: Case Study". JMIRx Med 2021 Aug;2(3):e32461 [FREE Full text] [doi: 10.2196/32461]

3. Anonymous. Peer Review of "The Influence of COVID-19 Vaccination on Daily Cases, Hospitalization, and Death Rate in Tennessee, United States: Case Study". JMIRx Med 2021 Aug;2(3):e32462 [FREE Full text] [doi: 10.2196/32462]

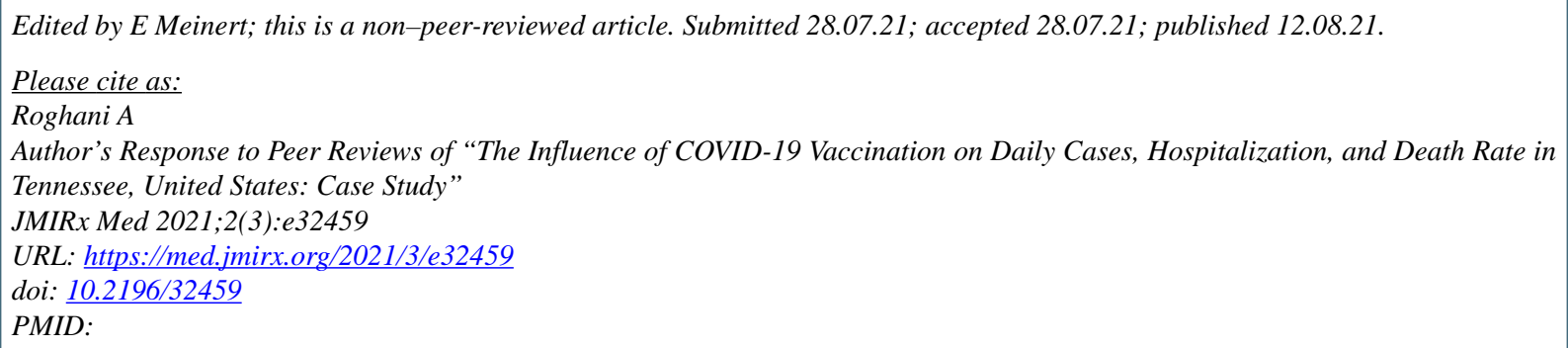

(CAli Roghani. Originally published in JMIRx Med (https://med.jmirx.org), 12.08.2021. This is an open-access article distributed under the terms of the Creative Commons Attribution License (https://creativecommons.org/licenses/by/4.0/), which permits unrestricted use, distribution, and reproduction in any medium, provided the original work, first published in JMIRx Med, is properly cited. The complete bibliographic information, a link to the original publication on https://med.jmirx.org/, as well as this copyright and license information must be included. 